\title{
A LOGÍSTICA NA EXPORTAÇÃO DA INDÚSTRIA DO PESCADO NO RIO GRANDE DO NORTE
}

\author{
E. L. N. SANTOS*, R. S. B. ARAÚJO, P. V. N. ARAÚJO e J. M. FILGUEIRA \\ Instituto Federal de Educação, Ciência e Tecnologia do Rio Grande do Norte \\ ericalusantos@gmail.com*
}

Artigo submetido em agosto/2015 e aceito em novembro/2015

DOI: 10.15628/empiricabr.2015.3339

\section{RESUMO}

O setor de pesca do Rio Grande do Norte traz benefícios sociais e econômicos para o Estado. O território potiguar é um dos maiores produtores de pescado (em especial do atum) do país, seja na forma artesanal ou industrial. 0 setor pesqueiro gera 40 mil empregos diretos no estado. Todavia, carece de investimentos significativos em infraestrutura logística. Objetivando melhorar o escoamento da produção, e assim manter a capacidade competitiva, investimentos em obras como a do terminal pesqueiro e do Aeroporto de São Gonçalo do Amarante poderiam contribuir na alavancagem deste segmento produtivo. Em função das características dos produtos, em especial o grau de perecibilidade destes, a consecução dos investimentos reduziria o tempo de transporte, que é um fator decisivo para a exportação do pescado. Inicialmente fez-se uma revisão da literatura nos temas correlatos à competitividade setorial como transporte, movimentação e cadeia produtiva do pescado, para servir de base para a definição da metodologia e operacionalização da pesquisa em análise do discurso, da qual participaram três gestores de empresas, por meio de entrevistas semiestruturadas. Destacam-se entre os resultados das análises a capacidade de adaptação das empresas locais a situações novas de modelo de negócios e a fragilidade estrutural no tocante a infraestrutura e tecnologia. Conclui-se que a atual condição da infraestrutura e dos meios logísticos, não são suficientes para o crescimento da atividade do Estado, requerendo das organizações públicas vinculadas ao setor e das empresas uma maior articulação na busca pela superação dos gargalos.

PALAVRAS-CHAVE: Indústria do Pescado, Logística, Competitividade.

\section{LOGISTICS EXPORT OF FISH INDUSTRY IN RIO GRANDE DO NORTE}

\begin{abstract}
The fishing industry of Rio Grande do Norte brings social and economic benefits for the state. The RN State territory is a big producer of fish (especially tuna) in the country, whether in artisanal or industrial. The fishing industry generates 40,000 direct jobs in the state. However, it lacks significant investments in logistics infrastructure. Aiming to improve the flow of production, and thereby maintain competitiveness, investments in works such as the fishing terminal and São Gonçalo do Amarante Airport could contribute to leverage this productive segment. Depending on the characteristics of
\end{abstract}

the products, in particular the degree of perishability of these, the achievement of investment would reduce transportation time, which is a decisive factor exporting fish. Initially we did a literature review of related competitiveness, transport and handling of fish production chain and to serve as a basis for defining the methodology and how the survey character of discourse analysis in which subjects participated in three companies through interviews. Concludes that the current condition of infrastructure and logistic facilities, is not sufficient for the growth of state activity.

KEYWORDS: Fish Industry, Logistics, Competitiveness. 


\section{INTRODUÇÃO}

A indústria da pesca é uma das mais antigas do Brasil, remonta à época colonial e desde então o Estado exerce sobre ela uma administração, através de leis, decretos e regulamentos, além da criação de órgãos específicos como a Superintendência do Desenvolvimento da Pesca (SUDEPE) em 1962.

A produção de pescado mundial em 2010 foi de 148 milhões de toneladas de peixes, crustáceos e moluscos (Food and Agriculture Organization of the Unidad Nations, 2013), proporcionando uma cota per capita de aproximadamente $19 \mathrm{~kg} / \mathrm{ano}$, mundialmente o peixe fornece proteína animal a aproximadamente $17 \%$ da população. Na produção mundial a pesca de captura predomina, o que se observa que a aquicultura vem destacando-se na crescente oferta total de peixes, passando de 13\% em 1990 para 40\% em 2010 (FAO, 2013).

A captura de peixes e da aquicultura é uma fonte de empregos e renda a população, com 55 milhões de pessoas com empregos diretos, e mais 220 milhões na indústria pesqueira mundial. Os estoques marinhos de peixes mantiveram-se relativamente estáveis desde 1970, em torno de 50 a 60\%, entretanto estudos constatam que é improvável a produção aumentar, a não ser que os planos de gestão eficazes fossem postos em pratica para assim reconstruir a sobrepesca dos estoques (FAO, 2013).

Na produção de alimentos a aquicultura representa o maior crescimento, com 60 milhões de toneladas de produção em 2010, a China apresenta a maior parte com 60 por cento da produção mundial (BOLETIM ESTATÍSTICO DA PESCA E AQUICULTURA, 2010).

Segundo o mesmo Boletim Estatístico no Brasil a produção é de mais de um milhão de toneladas/ano de pescado, gerando um PIB pesqueiro de $\mathrm{R} \$ 5$ bilhões, muitos profissionais são beneficiados com o setor que abrange cerca de 800 mil empregados, além do potencial elevado. Os estoques marinhos brasileiros que ocupam a costa até 200 metros de profundidade apontam para uma produção anual de entre 1,4 a 1,7 milhões de toneladas, e a pesca oceânica, subexplorada, com produção estimada em cerca de 200 mil toneladas/ano, abrangendo principalmente atuns, bonitos e anchoíta.

O Rio Grande do Norte exportou em 2011 cerca de US\$ 18 milhões, em peixes, posicionando-se como um dos itens mais importantes da pauta de exportação do Estado, até então representou um recorde histórico das exportações de pescado Potiguar (TRIBUNA DO NORTE, 2013).

\section{A LOGÍSTICA E A INDÚSTRIA DO PESCADO}

A importância da infraestrutura logística para as economias nacionais e para as empresas vem aumentando nos últimos anos. As boas condições logísticas de uma localização são fundamentais para apoiar o crescimento das exportações. Os governos de vários países são constantemente pressionados para melhorar sua qualidade de infraestrutura logística, assegurando condições para que as empresas localizadas em seus territórios sejam mais competitivas internacionalmente. É consenso entre diversos autores que a infraestrutura logística é um elo vital na cadeia total do comercio mundial, contribuindo para a competitividade internacional de um país (CHIN, TONGZON, 1998). 
O crescimento das exportações em alguns países tem colocado a infraestrutura logística destes à prova. No Brasil não é diferente, mas os problemas logísticos são gargalos à competitividade nacional, seja na ineficiência associada a intermodalidade ou da infraestrutura. As filas de caminhões nos portos, como o de Paranaguá/PR e Santos/SP são comuns (AGÊNCIA BRASIL, 2004; TRINDADE, 2004), navios esperando por mais de duas semanas para atracar (SAFATLE E RIBAMAR, 2004), estradas danificadas dificultando o tráfego e invasões e precarização do entorno das vias férreas são exemplos de alguns desafios relacionados à operação e qualidade da infraestrutura logística para o comércio exterior do país.

Na exportação brasileira de pescado de alto valor, no tocante à logística, predominam o modal marítimo e aéreo, em função das características de captura, armazenagem, transporte e perecibilidade do produto. No Rio Grande do Norte a produção para à exportação se caracteriza na primeira fase pela captura utilizando-se barcos, manuseio, movimentação e armazenagem na região portuária, transporte marítimo de longo curso ou transporte rodoviário em contêineres refrigerados para exportação via modal aéreo.

A principal vantagem do modal marítimo é a capacidade transportar mercadoria volumosa e pesada e o ter os custos de perdas e danos serem considerados baixos em relação a outros modais. E tendo como desvantagem a existência de problemas de transporte nos portos; transporte lento; e a forte influência do tempo. Entretanto a disponibilidade e a confiabilidade são afetadas pelas condições meteorologias (RIBEIRO E FERREIRA, 2002).

\subsection{Transporte por modal marítimo}

A existência de um sistema de transporte eficaz amplia a extensão do mercado para lugares distantes de produção, a menos que os custos de produção sejam muito menores que num segundo ponto de produção, a ponto de a diferença desses custos contrabalançar os custos de transporte para servir o segundo mercado. Entretanto, com melhores serviços de transporte, os custos de produtos postos em mercados mais distantes podem ser competitivos com aqueles de outros produtores que vendem nos mesmos mercados (BALLOU, 2004). O transporte marítimo representa a quase totalidade dos serviços de transporte no comércio exterior atualmente, responsável por cerca de $90 \%$ das cargas em função do seu baixo custo. Uma classificação do transporte hidroviário feita por Dias (1993) e alcança portos de mar e interiores, localizados em rios, dentro de um mesmo país ou de longo curso ou atracando em portos de dois ou mais países.

O transporte marítimo pode ser dividido em três formas de navegação, a saber: 1) Navegação de cabotagem. Realizada entre portos de um território; 2) Navegação interior. Realizada em hidrovias interiores, em percurso nacional ou internacional; 3) Navegação de longo curso. Utilizada dos portos de um território aos estrangeiros.

O transporte é um elemento essencial do custo total e está associado à cadeia de agregação de valores, que utiliza recursos temporais, financeiros e ambientais, e só utilizados quando realmente há aumento do valor dos produtos (BOWERSOX, 2006). A vantagem principal do transporte hidroviário é o baixo custo, composto basicamente por custos operacionais (capacidade relativamente grande, os custos fixos podem ser absorvidos pelos grandes volumes) (ARNOLD, 1999; CHOPRA e MEINDL, 2011). Todavia há limitações e Jacobs e Chase (2012) argumentam que os tempos de trânsito podem ser muito altos, e muitas partes do mundo não tem acesso direto ao 
transporte marítimo, limitando o serviço porta a porta (door-to-door) à condição em que o expedidor e o consignatário estiverem localizados em uma hidrovia.

No Rio Grande do Norte, apenas o Porto de Natal está habilitado a operar a exportação de pescado e é administrado pela CODERN - Companhia Docas do Rio Grande Norte, Sociedade de Economia Mista Federal.

\subsection{Transporte aéreo}

O transporte aéreo passa a ser levado em consideração por um número crescente de embarcadores como o serviço regular, embora suas taxas sejam mais de duas vezes superiores às do transporte rodoviário e 16 vezes mais caras que as do transporte ferroviário. $O$ grande atrativo do transporte aéreo é a sua inigualável rapidez origem-destino, principalmente em grandes distâncias (BALLOU, 2004).

O modal aéreo é mais adequado e utilizado para mercadorias de alto valor agregado, pequenos volumes ou com urgência na entrega. Possui algumas vantagens sobre o transporte marítimo por ser mais rápido, ter acesso facilitado e por apresentar menores custos com seguro, estocagem e embalagem, além de ser mais viável para remessa de amostras, brindes, bagagem desacompanhada, partes e peças de reposição, mercadorias perecíveis, entre outros. No Brasil, embora os aeroportos sejam dos poucos segmentos das infraestruturas que não sofreram um processo de degradação físico e operacional - pelo contrário, se expandiram e se modernizaram. Já os efeitos da abertura e as mudanças nos padrões de mercado e da competitividade repercutiram fortemente sobre as empresas. Assumiram a liderança no mercado interno aquelas empresas que conseguiram atuar em novos nichos e aumentar seus níveis de produtividade e eficiência empresarial. No entanto, ainda não se tem uma visão muito clara do que ocorrerá com a bandeira nacional no transporte de longo curso (BARAT, 2007).

O serviço de transporte aéreo existe nas formas legais comuns, contratado e privado. Existem sete tipos de serviço aéreo direto: 1) transportadores de carga geral de linha; 2) transportadores de carga geral (cargo); 3) linhas aéreas regionais; 4) transportadores suplementares; 5) táxi aéreo; 6) linhas aéreas comutadoras; 7) empresas internacionais (BALLOU, 2004).

Com o início das atividades do Aeroporto Governador Aluízio Alves, localizado em São Gonçalo do Amarante, a expectativa é otimista para as exportações no RN. Como principais destinos das exportações pesqueiras brasileiras temos, os Estados Unidos, Reino Unido, Alemanha, Itália, Espanha e Portugal (APRENDENDO A EXPORTAR, 2013).

\subsection{Cadeia produtiva do pescado e logística integrada}

A atividade pesqueira tem sua dinâmica associada a parâmetros biológicos, ecológicos, socioculturais, econômicos, institucionais e tecnológicos (SEBRAE-RJ, 2009). Trata-se de uma atividade complexa e de riscos, pois no seu fazer predomina um baixo nível de controle sobre as condições necessárias para o bom desempenho, principalmente nos países com baixo potencial tecnológico. A organização da produção e dos mercados está condicionada pela mobilidade dos recursos pesqueiros e pela complexidade do ecossistema e a atividade caracteriza-se como extrativa, sendo o mar o espaço produtivo natural pela reprodução (DIEGUES, 1983). 
Um primeiro elemento de análise da cadeia são os equipamentos necessários (ou meios) para a produção e os insumos para o desenvolvimento da atividade de pesca, através da captura (pesca extrativa). No caso da pesca extrativa, consideram-se como meios de produção as embarcações, os motores, os aparelhos; e os insumos básicos são a isca, o gelo, o combustível (diesel, gasolina, gás) e o rancho (alimentação da tripulação do barco). A produção da matériaprima base da cadeia produtiva do pescado fica a cargo dos pescadores e armadores de embarcações de pesca (PONTES, 2004).

O segmento de transformação é constituído pelas indústrias de beneficiamento do pescado, que processam a matéria-prima, agregando valor e produzindo alterações em sua forma de apresentação, de maneira a atender aos anseios dos consumidores finais e propiciar melhores condições de conservação ao produto. Para tanto se faz necessário condições apropriadas, como energia, água, gelo, embalagem, e bens para a produção, como máquinas, equipamentos, ferramentas, etc.

O segmento de distribuição envolve a infraestrutura e os modais de transporte, que são responsáveis por fazer o produto chegar aos pontos onde serão comercializados no atacado ou varejo, tais como armazém atacadista, peixarias, feiras e mercados, supermercados etc. Esse segmento envolve as empresas e colaboradores que fazem com que o pescado seja comercializado nos mercados interno e externo, os mecanismos tarifários, mercadológico e de informação, que dependem da capacidade da organização e competitividade do setor.

Segundo a FAO (Food and Agriculture Organization, 2010), o Brasil ocupa, a $18^{\circ}$ posição no ranking mundial referente à produção de pescado, e apresenta uma projeção de que o país será, em 2030, um dos maiores produtores mundiais, com valores estimados de produção de 20 milhões de toneladas anuais. Fator esse, decorrente de uma gigantesca área marinha ofertada para produção.

O Estado do Rio Grande do Norte tem potencial natural para a atividade pesqueira, pois, combina vários aspectos estratégicos como sua localização geográfica, condições ecológicas favoráveis, um Porto Internacional, grande faixa litorânea e proximidade de escoamento para os centros consumidores (PORTAL NO AR, 2013).

Em 2011 o RN exportou aproximadamente US\$ 18 milhões em peixes, esse foi um dos mais importantes itens da pauta de exportação do estado naquele ano. Esse número representou o recorde histórico das exportações de pescado do território potiguar (PORTAL NO AR, 2013). Esta produção recorde do Estado foi resultado da atuação de 11 barcos japoneses no ano de 2011, ultrapassando os Estados do Rio Grande do Sul e Santa Catarina nas exportações (ARAÚJO, 2013).

O desempenho potiguar é perceptível, nos últimos anos a partir de 2011, pois foi possível manter o crescimento da produção de pescado, mesmo com os problemas gerados pela crise econômica internacional, que afetou o poder de compra de milhões de pessoas nos países da Europa e nos Estados Unidos, consumidores diretos do produto. Um dos fatores para esse resultado foi à política de incentivos ao setor (ARAÚJO, 2013).

A empresa Atlântico Tuna localizada em Natal, conseguiu elevar a captura de atum e afins no país em duas mil toneladas no ano de 2011. Um aumento de mais de $400 \%$ do valor exportado, em dólar, pelo Rio Grande do Norte, o que mostra o impacto da tecnologia japonesa nos números (TRIBUNA DO NORTE, 2013). 
Segundo a Comissão Internacional para Conservação do Atum Atlântico (ICCAT), é possível capturar por ano, no Atlântico de forma sustentável, 500 mil toneladas de atum e afins - albacora branca, bandolim, lage, espadarte, bonito listrado.

\section{METODOLOGIA}

Considerando-se os objetivos da pesquisa, de caracterizar o processo logístico e analisar sua importância para a exportação de pescado no Rio Grande do Norte, optou-se por uma pesquisa qualitativa de caráter descritivo, na forma de estudo de caso único, no setor pesqueiro do RN, com base em fontes bibliográficas, documentais e entrevistas a gestores de empresas de pesca, utilizando-se questionários semiestruturados. Este tipo de abordagem, segundo Maanen (1979), compreende um conjunto de diferentes técnicas interpretativas, que visam a descrever e a decodificar os componentes de um sistema complexo de significados.

Foram realizadas, para a consolidação do estudo, três entrevistas de caráter exploratório, com representantes de empresas da área de exportação de pescado, mais especificamente do atum, em Natal-RN. As entrevistas aconteceram entre os meses de agosto e outubro de 2013.

Para responder ao questionamento exposto pela pesquisa inicialmente buscou-se analisar o segmento do pescado em relação à empresa para exportação. Alguns dados das empresas como: telefone e e-mail de contato foram preservados por questões de sigilo

\section{ANÁLISE DO AMBIENTE COMPETITIVO LOGÍSTICO DA INDÚSTRIA DO PESCADO NO RIO GRANDE DO NORTE}

O objetivo da logística é tornar disponíveis produtos e serviços no local onde são necessários, no momento em que são desejados. A logística envolve a integração de informações, transporte, estoque, armazenamento, manuseio de materiais e embalagem. Todas essas áreas que envolvem o trabalho logístico oferecem ampla variedade de tarefas estimulantes (BOWERSOX, 2007).

Segundo Araújo (2013), as embarcações usam o sistema de pesca com espinhéis de anzóis (longline), que são compostos por uma linha principal de nylon multifilamento trançado (PA\#60/1x8), com até $150 \mathrm{~km}$ de comprimento e 150 a 170 samburás, suspensos por boias (PVC, vermelho fluorescente, $270 \mathrm{~mm}$ de diâmetro) com cabos mistos multifilamento de nylon e poliéster (PA + PES), 6,9mm de diâmetro, que variam de 40 a 50mm de comprimento e distância entre si de $900 \mathrm{~m}$. Os anzóis permitem que os peixes capturados, em sua maioria, permaneçam vivos e, portanto, com grande qualidade para consumo, observado na Figura 1. 


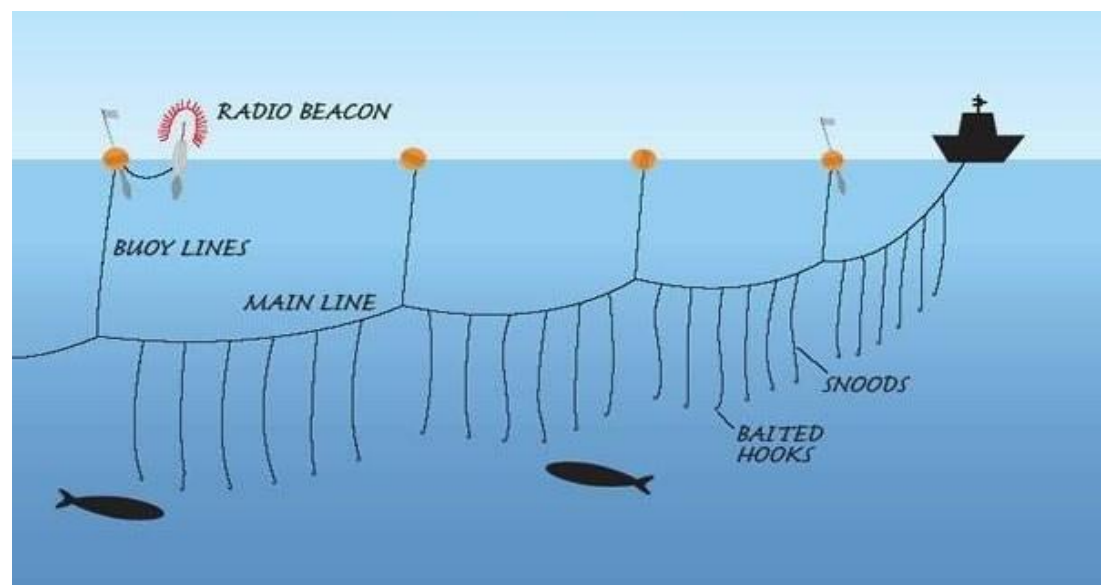

Figura 1 - Layout de um sistema de pesca com espinhel - longline

No processo pós captura os atuns são recolhidos a bordo, abatidos na região frontal da cabeça com introdução de uma pequena vara inoxidável perfurante, para que sejam imobilizados, sangrados com corte da veia arterial principal e eviscerados manualmente sobre colchão vazado de borracha. Logo em seguida, os peixes têm as brânquias e os opérculos removidos e as nadadeiras e a cauda cortadas, lavados internamente com água do mar e assim vão para o congelamento e acomodados em prateleiras com temperatura de $-60^{\circ} \mathrm{C}$. Após o congelamento cada peixe é pesado individualmente, devido ao formato irregular não são embalados e seguem para câmara de estocagem (ARAUJO, 2013).

Uma das empresas objeto deste estudo realiza o monitoramento das atividades pesqueiras, com um sistema que repassa dados sobre a produção capturada em números e peso de cada espécie, consolidando um sistema de informação, auxiliando no planejamento de descarga que é realizada após um período entre 03 e 04 meses de pesca, que ocorre direto do barco atuneiro (como pode ser visto na Figura 2), para o navio frigorífico ou para contêineres refrigerados.

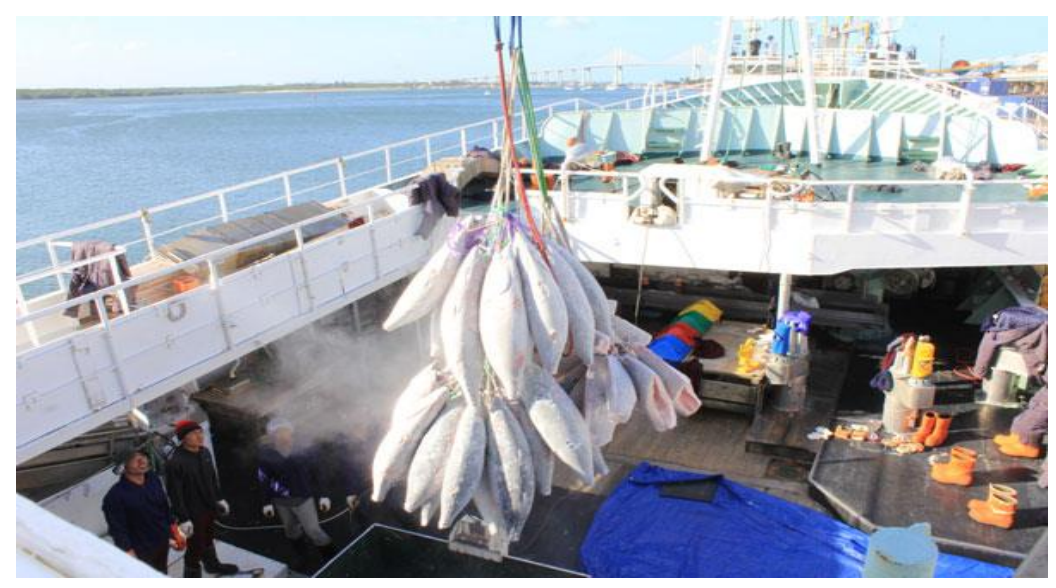

Figura 2 - Atuns sendo retirados de embarcações em Porto de Natal.

Iniciando a viagem de destino, que pode durar aproximadamente 90 dias, a empresa Pesqueira Nacional, argumenta que não encontra muitas possibilidades para baratear os custos logísticos e de produção do produto, pois os custos são dependentes dos materiais utilizados no processamento dos atuns como o preço do óleo e das iscas, que no caso da empresa, são importados do Uruguai e Argentina. O peixe já congelado e pronto para exportação é escoado à noite, já que se observa sua sensibilidade às mudanças de temperatura; ao chegar ao destino é 
feita a descarga, realizada com guinchos, nesse momento o tempo é fator chave para a qualidade do produto. A quantidade varia entre 20 e 27 toneladas por container e o retorno cerca de $50 \%$ é enviado para o exterior, a outra metade é voltada para o mercado interno. O modal mais vantajoso para o transportar os peixes congelados, ainda é o navio tanto pelo tamanho da carga quanto pelo preço.

As embarcações arrendadas no ano de 2011, por uma das empresas deste estudo, dedicadas à pesca de atum, espadarte e afins, possuem um motor principal (propulsão), dois motores auxiliares (geradores elétricos) e um motor reserva (acionado quando há pane em algum motor auxiliar), tendo capacidade média para armazenar 350.000 litros de óleo diesel e taxa de consumo diário de aproximadamente $2 \mathrm{t}$ de combustível (ARAUJO, 2013). Os anzóis do espinhel atingem cardumes que habitam zonas com profundidade superior a 250 metros, que evita a competição direta com a frota pesqueira nacional, que opera numa profundidade média de 100 metros. A baixa temperatura nos frigoríficos dentro dessas embarcações dá ao pescado uma qualidade especifica para sua comercialização no mercado do sushi, por exemplo, sendo considerado também o alto controle dos microrganismos e parasitas que podem existir.

A construção de uma vantagem competitiva baseada na competência logística diferenciará a empresa no mercado, dificultando a cópia por parte dos concorrentes (BOWERSOWX E CLOSS, 2001). A logística aparece neste cenário, como uma ferramenta insubstituível, ao contribuir para o aumento da flexibilidade, melhoria nos serviços e redução dos custos, fatores indispensáveis para qualquer empresa competir no cenário atual (DANTAS, 2000).

\subsection{Infraestrutura}

Uma das empresas afirma que o complexo do Porto de Natal com o Terminal Pesqueiro, cuja obra nunca foi finalizada, apresenta estrutura defasada e inadequada para o processamento do pescado para exportação. Logo, algumas melhorias citadas são evidentes, como reestruturação e finalização da obra do Terminal, tornando-o funcional, facilitando a exportação. A Ponte Newton Navarro e a falta de volume de pesca estão dificultando as rotas de navios cargueiros adequados à exportação do pescado supercongelado.

O Terminal Público Pesqueiro de Natal, localizado na Ribeira, zona Sul da capital potiguar, ainda não tendo sua obra concluída e até então parada. Em resposta, a Constremac empresa responsável pela construção, alega que o governo do RN não tem pago as parcelas pela obra; permanecendo a obra parada até uma resolução do problema. 


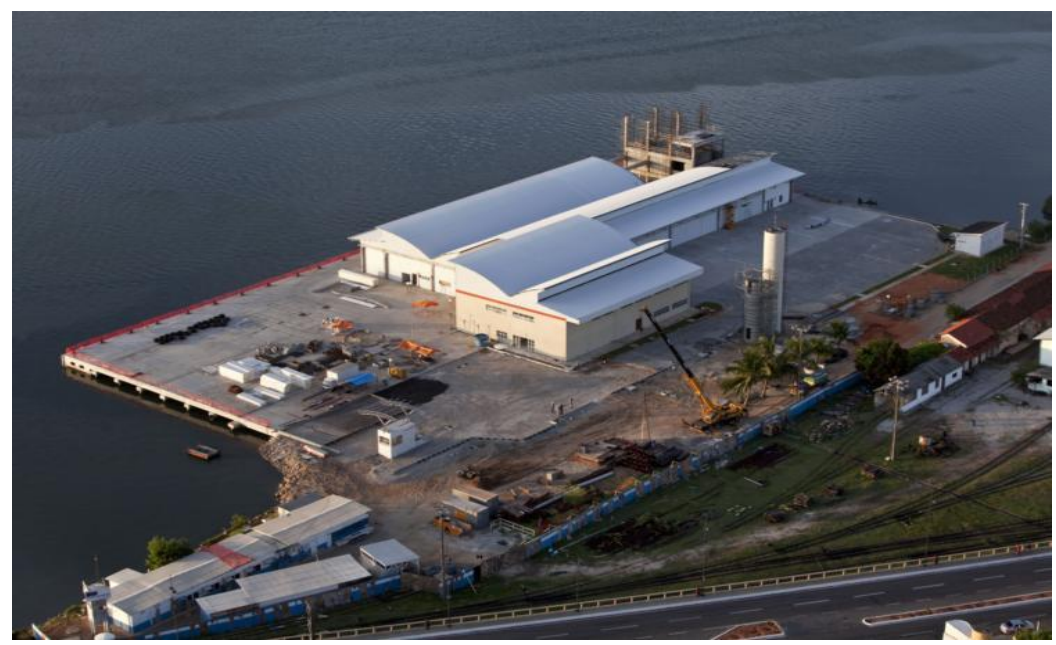

Figura 3 - Atuns sendo retirados de embarcações em Porto de Natal.

As obras do terminal pesqueiro começaram em 2009, sendo interrompidas em abril de 2011 por falta do pagamento a empresa, desde então, seguem paralisadas. Entretanto, 95\% já estão concluídas, ainda pendentes os serviços referentes às instalações elétricas, hidráulicas, do frigorifico e da fábrica de gelo. A expectativa é que o Terminal ofereça suporte para aumentar em $100 \%$ a quantidade de pescado movimentado pelo RN (TRIBUNA DO NORTE, 2014).

A empresa Atlântico Tuna, afirma ter equipamentos adequados e tecnologia suficiente para captura dos peixes, utilizando-se da arte de pesca Espinhel Pelágico e linhas de pesca entre 120 a $200 \mathrm{~km}$.

Já as demais empresas não comentaram sobre a falta de tecnologia, apenas afirmaram utilizar equipamentos e tecnologia espanhola para a captura do produto, não obtendo tanto sucesso quanto a japonesa. Vale ressaltar que no modelo de pesca Espanhol, algumas embarcações não realizam o supercongelamento, mas sim o acondicionamento em gelo.

É preciso criar uma nova geração de embarcações voltada a este tipo de captura e acondicionamento com super congelamento, contribuindo com a frota de forma a aumentar a produtividade, além disso, a tecnologia exige níveis de qualificação mais elevados, precisando investir nas pessoas, não só qualificar os profissionais que já atuam na área, como também criar uma nova geração, que possa manusear esta tecnologia.

A flexibilização da importação de embarcações atuneiras seria particularmente conveniente, no caso das embarcações que já se encontram em operação no Brasil, através do arrendamento, uma vez que a empresa arrendatária, além de já estar plenamente inserida na cadeia produtiva da pesca de atum, estaria importando uma embarcação cujos aspectos técnicos e operacionais já seriam completamente conhecidos e dominados. A importação poderia, inclusive, ser apresentada como uma alternativa à continuação das atividades da embarcação no País, uma vez finalizado o período autorizado de arrendamento.

A abertura ocorrida no setor para que essas embarcações atuassem no Brasil, representou crescimento da oferta do pescado de alta qualidade nos mercados interno e de exportação, e promoveu a geração de emprego e renda na cadeia produtiva do setor pesqueiro (HAZIN, 2006). A entrada da pesca oceânica em profundidade a partir do Porto de Natal foi facilitada pela proximidade da costa brasileira das principais áreas de pesca no Atlântico, pelo alto valor comercial 
deste tipo de pescado para exportação; pelo potencial de produção de proteína animal de baixo custo; pelo ciclo de vida relativamente independente dos ecossistemas costeiros e pelo elevado peso individual dos peixes (HAZIN, 2012).

A consolidação do Brasil como um País importante na pesca oceânica do Atlântico Sul, porém, só poderá se concretizar se todo o esforço de desenvolvimento pesqueiro for adequadamente calçado pela condução de pesquisas que permitam, não apenas gerar as informações biológicas essenciais para uma correta avaliação dos estoques explorados, aspecto crucial para a construção de medidas de ordenamento que possam assegurar a sustentabilidade da atividade, mas também informações técnicas que possam contribuir para aumentar a competitividade e a eficiência da frota nacional. Considerando-se que a defesa de qualquer direito só se sustenta quando devidamente amparada pelo adequado cumprimento dos deveres correlatos, pode-se igualmente afirmar que o desenvolvimento de pesquisas científicas sobre os atuns e afins do Atlântico se configura como um importante ativo no processo de negociação necessário à sustentação das aspirações brasileiras de crescimento de sua participação na pesca desses importantes recursos pesqueiros.

A construção do Aeroporto de São Gonçalo do Amarante trouxe expectativa positiva para as exportações no RN, no entanto desde sua abertura e funcionamento das instalações, as operações foram dificultadas, na visão de um dos entrevistados, ele afirmou que o setor pesqueiro está apreensivo com a mudança, não sabendo como serão as operações de movimentação de cargas: "O pescado representava 70\% da movimentação de carga no aeroporto Augusto Severo e $90 \%$ do nosso produto é exportado de avião. O RN é o maior exportador de atum do país. Temos que saber como vai ser o procedimento" relatou o empresário. Um dos entrevistados aponta a falta de um acesso que torne o trânsito mais fácil ao novo aeroporto, e as restrições de horário ao tráfego de carretas no município de Natal como as principais dificuldades para os exportadores locais de pescado.

\section{CONSIDERAÇÕES FINAIS}

Observou-se junto às empresas que os gargalos logísticos são relevantes para a competitividade interna e externa do segmento, seja pela condição de defasagem da estruturação do Porto de Natal em termos de equipamentos e área de estocagem, ou pela falta de navegação de cabotagem, que geram desvantagem ao setor e dificuldades de distribuição da produção. Cabe destacar o atraso na conclusão do terminal pesqueiro e suas instalações.

Também foi possível constatar problemas logísticos no tocante ao transporte pela falta de investimentos em embarcações e tecnologia, por parte das empresas, que poderia se refletir no aumento da produção e na melhoria da competitividade. Na coleta dos dados foi visto que a empresa Atlântico Tuna é a única que dispõe de tecnologia adequada para pesca em grandes profundidades na captura de atuns. As embarcações japonesas arrendadas por esta empresa são dotadas de modernos equipamentos para a finalidade tecno-operacional a que se destinam, de modo que sua estratégia e táticas de captura são responsáveis por um considerável aumento da produção de pescado de origem oceânica ocorrido em 2011 (ARAÚJO, 2013).

Verificou-se na fala dos entrevistados que a indústria pesqueira de produção oceânica no Brasil necessita realizar investimentos importantes na constituição de uma frota nacional para 
desenvolver o potencial pesqueiro no alto mar, mas para isso é fundamental uma mudança na legislação, na mentalidade dos governantes e na postura dos empresários. Além disso, é evidente uma preocupação pela qualificação profissional dos envolvidos no processo produtivo, uma vez que grande parte dos pescadores profissionais envolvidos na pesca de atuns possuem média idade e baixa escolaridade. Uma possível solução para esse último problema, é o aumento da oferta de cursos profissionais marítimos. Nos últimos anos, os institutos federais de ensino básico, técnico e tecnológico se credenciaram para ofertar esses cursos em seus estados. O Instituto Federal de Educação, Ciência e Tecnologia do Rio Grande do Norte (IFRN), assinou o convênio com a Marinha do Brasil e estima-se que no início do segundo semestre de 2015 , inicie a primeira turma de formação para Pescador Profissional, com habilitação da Marinha do Brasil.

Algumas dificuldades foram consideradas por todas as empresas analisadas, foram elas: a proximidade da cidade de Natal não é suficiente para desenvolver a exportação de pescado e a produção máxima alcançada não foi suficiente para atender as demandas do mercado internacional. Este hiato aponta para a necessidade urgente de ações estruturantes, pois o mercado existe.

Outra dificuldade unânime relatada foi a da exportação por via aérea, visto que as empresas que voam para os mercados que mais demandam limitam a quantidade de peixe fresco que podem levar de forma proporcional à quantidade de voos, e estes podem oscilar de acordo com as estações do ano.

Em síntese, o resultado da pesquisa sinaliza para a necessidade de reestruturação tanto da logística do Estado quanto do segmento empresarial do pescado local visando sua própria sobrevivência.

\section{REFERÊNCIAS}

1. AGÊNCIA BRASIL. Caminhões no porto de Paranaguá formam filas de 85 quilômetros. Disponível em: <www.ceol.com.br>. Acesso em: 16 abril 2004.

2. Aprendendo a exportar. Pescados no Brasil. Disponível em: <http://www.aprendendoaexpor tar.gov.br/_pescados/>. Acesso em: 31 jul. 2013.

3. AQUICULTURA, Ministério Da Pesca E. Pesca Industrial. Disponível em: <http://www.mpa.gov. br/pescampa/industrial>. Acesso em: 31 jul. 2013.

4. ARAÚJO, Paulo Victor do Nascimento et al. Descrições gerais da frota japonesa arrendada para a pesca de atuns e afins na zona econômica exclusiva do brasil. Labomar: CIÊNCIAS DO MAR, Fortaleza, v. 2, n. 46, p.55-63, jan. 2013. Disponível em: <http://www.labomar.ufc.br/>. Acesso em: 15 jul. 2014.

5. ARNOLD, J. R. T. Administração de materiais. São Paulo: Atlas, 1999.

6. BALLOU, Ronald H.. GERENCIAMENTO DA CADEIA DE SUPRIMENTOS/ LOGÍSTICA EMRPESARIAL. SÃo Paulo: Bookman, 2004.

7. BARAT, Josef. LOGÍSTICA E TRANSPORTE NO PROCESSO DE GLOBALIZAÇÃO: OPORTUNIDADES PARA O BRASIL. São Paulo: Unesp, 2007. Disponível em: <https://books.google.com.br/books ?id=C6FnwPUXFF4C\&printsec =frontcover\&dq=logistica\&hl=ptBR\&sa=X\&ei=acFLVbzqEomYg wSW6oEg\&ved=0CFUQ6AEwCA\#v=onepage\&q=logistica\&f=false>. Acesso em: 07 maio 2015. 
8. BOWERSOX, D; CLOSS, D. C. e COOPER, M. B. Gestão logística de cadeias de suprimentos. Porto Alegre: Bookman, 2006.

9. BOWERSOX, Donald J., CLOSS, David J. Logística Empresarial. São Paulo: Atlas 2001.

10. CHIN, A.; TONGZON, J. Maintaining Singapore as a major shipping and air transport hub. In: Toh, T. (Ed.), Competitiveness of the Singapore Economy. Singapore: Singapore University Press, p. 83-114, 1998.

11. CHOPRA, S. e MEINDL, P. Gestão da cadeia de suprimentos: estratégia, planejamento e operações. 4 ed. São Paulo: Pearson, 2011.

12. DIAS, Marco Aurélio P. - Administração de materiais: uma abordagem logística, São Paulo: Atlas, 1993.

13. Diegues, A.C. 1983. PESCADORES, CAMPONESES E TRABALHADORES DO MAR. São Paulo: Ática.

14. FAO, 1997. (FAO Documento Técnico Sobre as Pescas 334). Disponível em: http://www.fao .org/DOCREP/003/T1768P/T1768P01.htm. Acesso em 04/04/06.

15. HAZIN, Fábio Hissa Vieira. A PESCA OCEÂNICA NO BRASIL NO SÉCULO 21. Revista Brasileira de Engenharia de Pesca, Pernanbuco, p.60-75, 01 jan. 2007. Disponível em: <http://ppg.revistas. uema.br/index.php/REPESCA/search/results>. Acesso em: 27 jun. 2012.

16. JACOBS, F. R. e CHASE, R. B. Administração de operações e da cadeia de suprimentos. 13 e.d. Porto Alegre: AMGH, 2012.

17. NORTE, Tribuna do. A pesca oceânica precisa de um salto tecnológico. Disponível em: <http://tribunadonorte.com.br/noticia/a-pesca-oceanica-precisa-de-um-salto-tecnologico/2 26397>. Acesso em: 08 nov. 2012.

18. PONTES, Rigoberto Neide. A cadeia produtiva do pescado do amazonas: um enfoque pelo agronegócio. Disponível em: <http://www.mpa.gov.br/pescampa/industrial>. Acesso em: 31 jul. 2013.

19. RIBEIRO, Priscilla Cistina Cabral; FERREIRA, Karina Araújo. LOGÍSTICA E TRANSPORTES: UMA DISCUSSÃO SOBRE OS MODAIS DE TRANSPORTE E O PANORAMA BRASILEIRO. 2002. Disponível em: <http://tecspace.com.br/paginas/aula/mdt/artigo01-MDL.pdf>. Acesso em: 22 ago. 2014.

20. RIBEIRO, Priscilla Cistina Cabral; FERREIRA, Karina AraÚjo. LOGÍSTICA E TRANSPORTES: UMA DISCUSSÃO SOBRE OS MODAIS DE TRANSPORTE E O PANORAMA BRASILEIRO. 2002. Disponível em: <http://tecspace.com.br/paginas/aula/mdt/artigo01-MDL.pdf>. Acesso em: 22 ago. 2014.

21. SAFATLE, C.; RIBAMAR, O. Empresas pagam por deficiência de portos. Valor Econômico, 14 mai. 2004.

22. TRINDADE, R. Porto de Santos funcionará 24 horas. Valor Econômico, 5 mai. 2004.

23. VIANNA, Marcelo (Organizador). DIAGNÓSTICO DA CADEIA PRODUTIVA DA PESCA MARÍTIMA NO RIO DE JANEIRO/Relatório de Pesquisa. Rio de Janeiro: FAERJ: SEBRAE-RJ, 2009. 